\title{
Ecological Aspects of Urban Agriculture in the Context of Sustainability
}

\section{Zornitsa Stoyanova*}

\section{Summary}

Achieving a more sustainable and environmentally friendly approach, following the concepts of sustainable development and searching solutions for improving the quality of life in the context of urban agriculture requires a determination of the environmental aspects of this type of practices in the context of sustainable development. Sustainable urban agriculture combines all the characteristics of urban agriculture, implemented in the concept of sustainability. The aim of the paper is based on the assessment of the ecological impact of urban agriculture to determine its possibilities for improving the life quality in Bulgaria.

The paper has the following structure: 1) Literature review of the relevant author's findings directed at sustainable urban agriculture; 2) Methodological framework of the study; 3) Analysis of the respondents' opinion about the ecological aspects of urban agriculture for improving the life quality; 4) General conclusions related to the ecological aspects of urban agriculture for improving the life quality.

Ecological aspects of urban agriculture to improve the quality of life are revealed on the basis of the respondents' assessments in terms of the environmental benefits of urban agriculture, the profile of the customers of the products from urban agriculture, the profile of urban agricultural products, applied practices and production methods, pollution of natural resources etc. Some of the conclusions in the paper are related to the opportunities of urban agriculture to ensure food security and food resources in an environmentally friendly manner, optimize and save the use of natural resources, implement green practices, create local employment and encourage the development of the regions.

The results are part of the scientific project DN 05/18 Urban agriculture as a strategy for improving the quality of life of urban communities, funded by the Bulgarian research fund.

Keywords: urban agriculture, sustainability, ecology, life quality

JEL: Q1, Q01

\section{Introduction}

Iban sustainability is connected with the viability of the city as a complex system, the life quality of the citizens and the ability of the environment to support urban activities. Some authors define this concept in terms of economic urban sustainability, its potential to achieve a qualitatively new level of socio-economic, demographic and technological results that in the long run aspect strengthen the foundations of the urban system. Other authors emphasize the principles of justice, equity and participation

* UNWE, Department: Economics of Natural Resources 


\section{Articles}

of citizens in land development processes. In this regard Basiago (1999) considers that urban environmental sustainability is the achievement of a viable balance between land development and environmental systems. Achieving urban sustainability in economic, social and environmental contexts is possible through the implementation of sustainable integrated urban development. It requires the use of an integrated approach with regard to: 1) physical urban renewal measures; 2) measures for improving education, economic development, social inclusion and environmental protection, development of strong partnerships involving local citizens, civil society, the local economy and different levels of governance to address the challenges the urban areas face - economic, ecological, climatic, social and demographic (EC, 2014). One of the possibilities for achieving sustainable integrated urban development is sustainable urban agriculture. Integrating sustainability in the concept of urban agriculture requires a comprehensive approach to urban farming practices, not only from a technical point of view, but also from the resource use perspective. Producers strive for a more sustainable and environmentally friendly approach, and the concept of sustainable development has to be implemented in the urban agricultural practices.

\section{Literature review of the sustainable urban agriculture and its ecological aspects}

The first studies related to urban agriculture date from the 1970s. Authors as Jamal and Mortez (2004) consider that city and agriculture have an old relationship. Later in the 1990s, urban agriculture is perceived as an activity that provides food and additional income to poor urban residents in developing countries (Dubelling et al., 2010). Battersby and Marshak (2013) consider that in recent decades, urban agriculture is a solution for different urban challenges as food security, poverty and urban waste management. Governments and international associations accept urban agriculture as a strategy for ensuring the food security and ecological sustainability of cities (Jamal and Mortez, 2004). The reasons for the increase of the importance of urban agriculture are the increase of urban population and food demand. Lohrberg et al. (2016) consider that the benefit of urban agriculture is not only food production in the city, but it has many different non-production-oriented goals in an economic, social, ecological and educational perspective.

There are many studies that present the integration of sustainability in the concept of urban agriculture. According some authors (Hoornweg, Munro-Faure, 2008), sustainable urban agriculture can be addressed in two respects. On one hand, from an economic point of view, the assessment of the economic sustainability of urban agriculture does not differ materially from the economic sustainability of agriculture, because it depends on the value of some of the basic natural resources as land, water and labor that compete to be utilized for other uses in the urban environment. In this respect, the economic sustainability of urban agriculture depends on the application of specialized and advanced technologies, which will optimally use the resources. On the other hand, sustainable urban agriculture can also be addressed by incorporating some cultural and social dimensions such as securing urban food supply and creating socio-economic and socio-cultural security networks. At the same time, sustainable urban agriculture 


\section{Articles}

reduces environmental risks as the use of pesticides is limited and encourages the use of biological chemicals and fertilizers. Sustainable urban agriculture leads to the transformation of agricultural production into less chemically intensive (Deelstra, Girardet, 2000). Authors as de Zeeuw (2011) consider that urban agriculture is a practice that has a positive impact on the state of the environment, because by practicing it, this reduces the distance travelled by food, leads to a reduction of greenhouse gas emissions and contributes to the improvement of global climate change. Eigenbrod and Gruda (2015) added that recycling and waste disposal is one of the ecological benefits from urban agriculture.

Mougeot (2010) considers urban agriculture could become sustainable if land use is combined and the land is used for different uses. Sustainable urban agriculture achieves the diversity of production systems and its reconciliation with a wide range of urban activities. Free land plays an important role in the sustainability of cities. The main issue is providing land for urban agriculture in a longterm perspective that allows sustainability and investment. The sustainability of agriculture in and around cities also depends on the management of catchment areas and landscapes. Optimal management of natural resources in and around cities is a mandatory condition for sustainable urban and suburban agriculture (Hoornweg, Munro-Faure, 2008).

Authors as Torres-Lima et al. (1994) enrich the concept of sustainable urban agriculture by considering that it should be seen not only in terms of environmental sustainability but also in terms of regional development policies
Ecological Aspects of Urban Agriculture in the Context of Sustainability

including the economic, social and cultural aspects of urban development.

Hoornweg, Munro-Faure (2008) share a view that sustainable urban agriculture contributes to ensuring food security and food resources in cities and the creation of employment through:

* Providing self-consumption, achieving healthy food and saving food costs;

* Providing income by selling excess production;

* Improving the supply of fresh and micro-nutrient foods at competitive prices at local markets;

* Ensuring continuity of green cover by landscape management and the use of agro-forest systems, hedges and tree sticks.

Scientific researches define different ecological aspects of urban agriculture. Cofie et al. (2006) define ecological aspects of urban agriculture as supporting waste disposal and solving the related to this problems. Some of the solutions are connected with compost production, irrigation with wastewater etc. Eigenbrod and Gruda (2015) also connect the ecological aspects of urban agriculture with the recycling of urban wastes and its support for waste disposal. Blanke and Burdick (2005) shared another aspect of the environmental benefits and they point out the reduction of the distance travelled by food resources. Konijnendijk et al. (2004) share a view that urban agriculture contributes to greening the urban areas, improvement of the urban micro-climate, maintaining biodiversity. Ghosh (2004) also added the role of urban agriculture for greenhouse gas emissions and climate change. According Golden 


\section{Articles}

(2006) the ecological impacts of urban agriculture are related to waste recycling, water management, restoration of toxic and damaged land, reduction of thermal island effect in settlements etc. FAO (2007) defines the contributions of urban agriculture as: urban environmental management in connection with waste disposal, reducing the ecological footprint by producing fresh foods close to the consumers, reducing energy use for transport, packaging etc.

\section{Materials and methods}

The aim of the paper is based on the assessment of the ecological aspect of urban agriculture to determine its possibilities for improving the life quality.

The paper has the following structure: 1) Literature review of the relevant author's findings directed at sustainable urban agriculture; 2) Methodological framework of the study; 3) Analysis of respondents' opinion about the ecological aspects of urban agriculture for improving the life quality; 4) According to the discussion and results, general conclusions related to ecological aspects of urban agriculture for improving the life quality (food security and food resources, production in an environmentally friendly way, safety use of natural resources, implementation of green practices, creation of local employment, encouragement of the regional development) in Bulgaria are drawn.

The survey was held in 2018, and the target group for the survey included experts and stakeholders engaged in urban agricultural practices. For the purpose of this paper are analyzed 25 in-depth interviews with key representatives of civic groups and NGOs engaged in urban agricultural activities, distributors and producers of agricultural products, representatives of social institutions with a potential for the development of urban agriculture and 5 focus group discussions with active participants in informal groups and NGOs developing urban agriculture, representatives of the local authorities in relation with the practices of urban agriculture. The interviewed had to define and asses the environmental benefits of urban agriculture, the profile of the customers of the products from urban agriculture, the profile of urban agricultural products, applied practices and production methods, pollution of natural resources etc. The respondents had to share their view about the potential of urban agriculture to create environmental benefits in the cities. In this connection they had to answer the questions related to the possibilities of urban agriculture to improve the environmental situation in the cities, to define the profile of the customers of the products from urban agriculture, the profile of urban agricultural products, applied practices and production methods, pollution of natural resources etc. Some of the criteria set out in the study are as follows - access to clean air, water, land, non-toxic materials and preservation of urban biodiversity, conservation of resources and energy efficiency improvement, creation of a variety of green areas and landscapes, policies and measures for waste management. The framework of the study is presented on the Figure 1.

The results are part of scientific project DN 05/18 Urban agriculture as a strategy for improving the quality of life of urban communities, funded by the Bulgarian science fund. 
Figure 1. Methodological framework

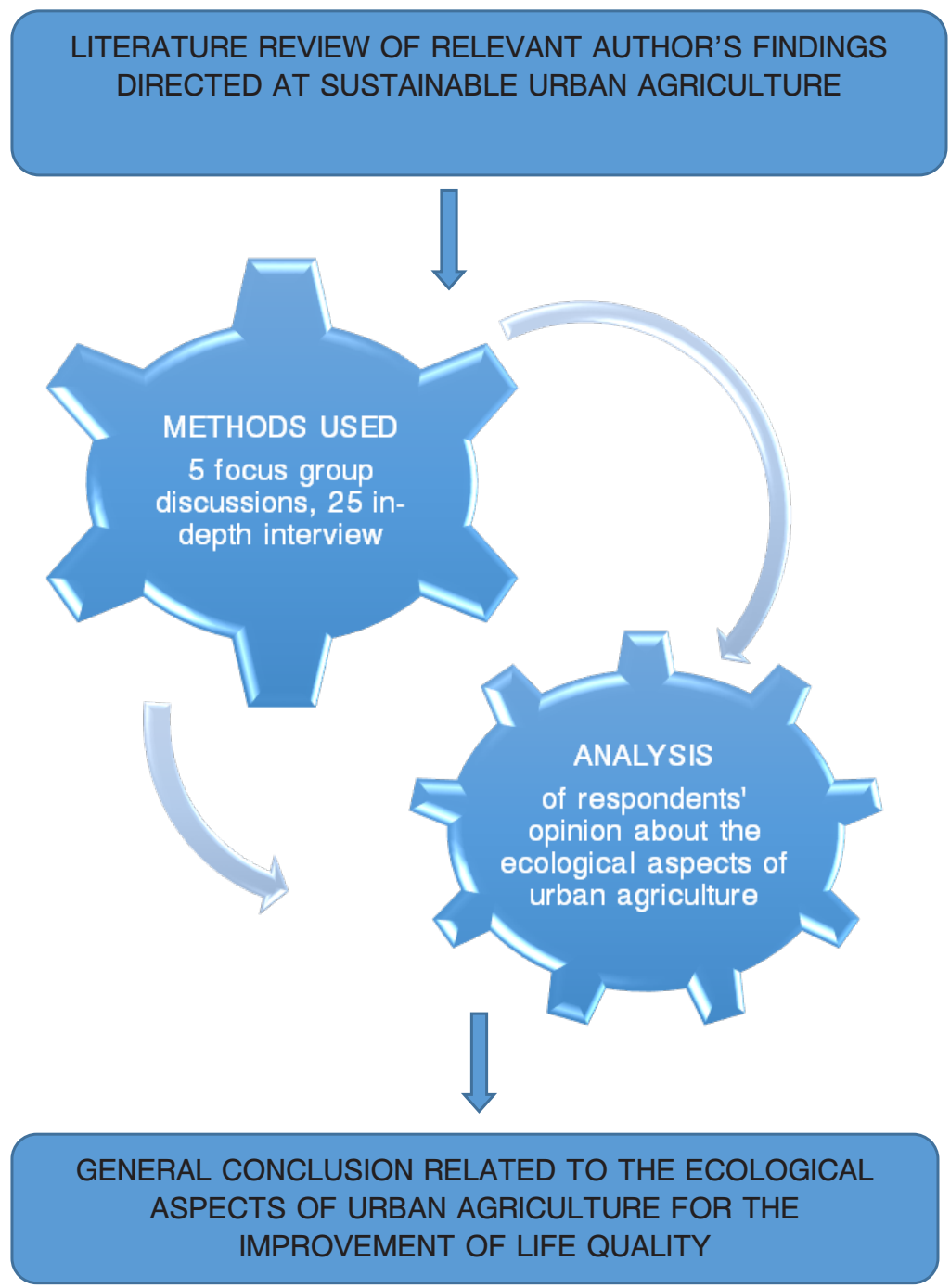

\section{Results and discussion}

\section{Ecological aspects of urban agriculture to} improve the life quality

Assessments of respondents in terms of the environmental benefits of urban agriculture, the profile of the customers of the products from urban agriculture, the profile of urban agricultural products, applied practices and production methods, pollution of natural resources make it possible to highlight the ecological aspects of urban agriculture to improve the quality of life.

Respondents associate urban agriculture with the production of high-quality production grown in a natural way without the use of pesticides and chemical preparations. On the question of the environmental friendliness of products from urban agriculture, producers share the view that they are environmentally 


\section{Articles}

friendly as they are produced without fertilizers, pesticides and chemicals, pest and soil treatments are alternative and also environmentally friendly. Production is defined as being better in terms of taste and technological practices, and this results in greater life satisfaction.

According to the respondents' opinion, products from urban agriculture are not for mass distribution but some of them believe that this type of products should be promoted to show that even in an urban environment it is possible to produce high quality products and create consumer attitudes to using ecologically produced food resources and this leads to the improvement of the quality of life in the cities.

Some of the respondents who are agricultural producers determine the products' profile as endangered - varieties, breeds. Table 1 presents the main respondents' views about the type of products, their ecological focus and the channel of distribution of products from urban agriculture.

Table 1. Main views related to the ecological focus and distribution of products from urban agriculture

\begin{tabular}{|c|c|}
\hline $\begin{array}{l}\text { Opinions about the ecological focus of products from } \\
\text { urban agriculture }\end{array}$ & $\begin{array}{l}\text { Opinions about the distribution of products from urban } \\
\text { agriculture }\end{array}$ \\
\hline $\begin{array}{l}\text { - High-quality output, not based on pesticides } \\
\text { and chemical preparations use, but } \\
\text { produced in a natural way .... the production } \\
\text { is better as consumer characteristics; } \\
\text { - More delicious, healthy, unsprayed } \\
\text { production without the use of genetically } \\
\text { modified crops; } \\
\text { - Absolutely ecologically clean, only organic } \\
\text { fertilizers and compost are used, without } \\
\text { pesticides. Alternative ways to combat pests } \\
\text { are applied. For example: against snail is } \\
\text { used eggshells; castor is planted against a } \\
\text { mole; and other spices with strong smell are } \\
\text { planted also; } \\
\text { - Conventional crops are sprayed with plant } \\
\text { protection products (herbicides, pesticides) } \\
\text { and urban agriculture usually does not } \\
\text { use fertilizers other than compost, which } \\
\text { producers prepare themselves, and so the } \\
\text { production is environmentally friendly. }\end{array}$ & $\begin{array}{l}\text { - Products from urban agriculture are not } \\
\text { produced for sale and for mass distribution. } \\
\text { The most important thing is diversity and } \\
\text { being environmentally friendly; } \\
\text { - The production from urban agriculture is on } \\
\text { a small scale, it is not intended for sale, but } \\
\text { it is for the own needs of the people who } \\
\text { produce it. The purpose for its consumption } \\
\text { doesn't matter - It could be for household } \\
\text { needs or a vegetable garden in a school } \\
\text { that is used for an educational purpose. The } \\
\text { production is healthy. } \\
\text { - Products are distributed on an informal } \\
\text { basis. People find producers of agricultural } \\
\text { production and provide environmentally } \\
\text { friendly production. Everything is organized } \\
\text { "from mouth to mouth", from friend to friend } \\
\text { and although these forms are illegitimate, } \\
\text { people are actively looking for them because } \\
\text { they want to have an easy and secure } \\
\text { access to environmentally friendly products. }\end{array}$ \\
\hline
\end{tabular}

Source: own findings

The motives for practicing urban agriculture are different. Most of them are connected with the environmental thinking and attitude of the producer. Reasons motivating respondents to realize urban agriculture are defined as:

$\checkmark$ Relationship to land and agriculture. A motive for urban agriculture producers is the genetic connection with the land of their ancestors and the agricultural practice from early childhood. Motivation is related to the past connection with land and passion and love of agriculture. The willingness of respondents to be a role model for their children, to show them how to create productions through work, is a reason that further motivates them. For some of the producers the idea of dealing with such practices occurs acciden- 


\section{Articles}

tally and the reason is the passion and desire to be engaged in farming.

"There is no motivation for me, my genetic background - my grandparents were agricultural producers and I was born and lived in a village. As a child I participated in all kinds of activities -winter and summer. In summer we worked in gardens and in the field. "- S.T., man

$\checkmark$ Satisfaction from creating a product that is environmentally friendly. The producers are motivated and receive inspiration from the first results obtained and the joy of production creation, although small in volume. Respondents shared their satisfaction from tracking the production process of their own production. However, they are also motivated by the idea of creating an ecological product that will be consumed by their relatives. Some of them consider that the idea of starting practicing urban agriculture originates in order to provide ecologically clean food for children and their relatives.

$\checkmark$ Friends and relatives. Some respondents are motivated by friends and start practicing urban agriculture out of curiosity. They are driven by their interest in creating something interesting, the idea they learned from friends and acquaintances. Consequently, the practice of urban agriculture, the contact with other people in the group, the desire to obtain a satisfying result, the passion for general activity is an additional motive. Practicing this activity is associated with the possibility for experimentation.

"A good friend invited me and because I was 18 years old (relatively small) and I was curious. This was an invitation from a friend and was something interesting. Then the other people also motivated me - passion and desire was the production of the first picked parsnips,
Ecological Aspects of Urban Agriculture in the Context of Sustainability

onions, zucchini - it was very nice and pleasant. That's how we were inspired "-Tz. P, woman.

$\checkmark$ Sustainable development of cities. Practicing urban agriculture is also being pursued in order to make the city sustainable, focusing on the environmentally friendly use of free spaces, organizing cultural events and creating thinking about the implementation of practices that have a positive impact on people and the environment in cities that surrounds the people.

"We want our city to develop sustainably and well; these spaces should not be just gardens. The aim of these places is different events to happen inside, and even cultural events. We organized a library in our garden for example - it's not broken, it's not spoiled, there's no stolen book. "- P.W., man

To achieve the quality of the products, some respondents consider that as producers they meet the standards for applying good agricultural practices. They identify them as ecological and most of them apply methods as permaculture, biodynamic farming. Practices (composting, mulching) are used to conserve soil and water resources and produce ecological products. According to the respondents' view, the way to achieve cleaner production is to produce without chemical fertilizers, preparations, fertilization to be carried out with manure, some bio preparations are prepared by the producer.

Although urban agricultural producers define urban agriculture as environmentally friendly and produced through good agricultural practices, some of them consider they did not make measurements of soil, air and water pollution in the production area. Measurements are related to soil characterization to increase yields. Another part of the respondents share a view that they made measurements mainly of soil contamination (Figure 2). 


\section{Articles}

Figure 2. Measurements of soil, air and water pollution organized by the producers

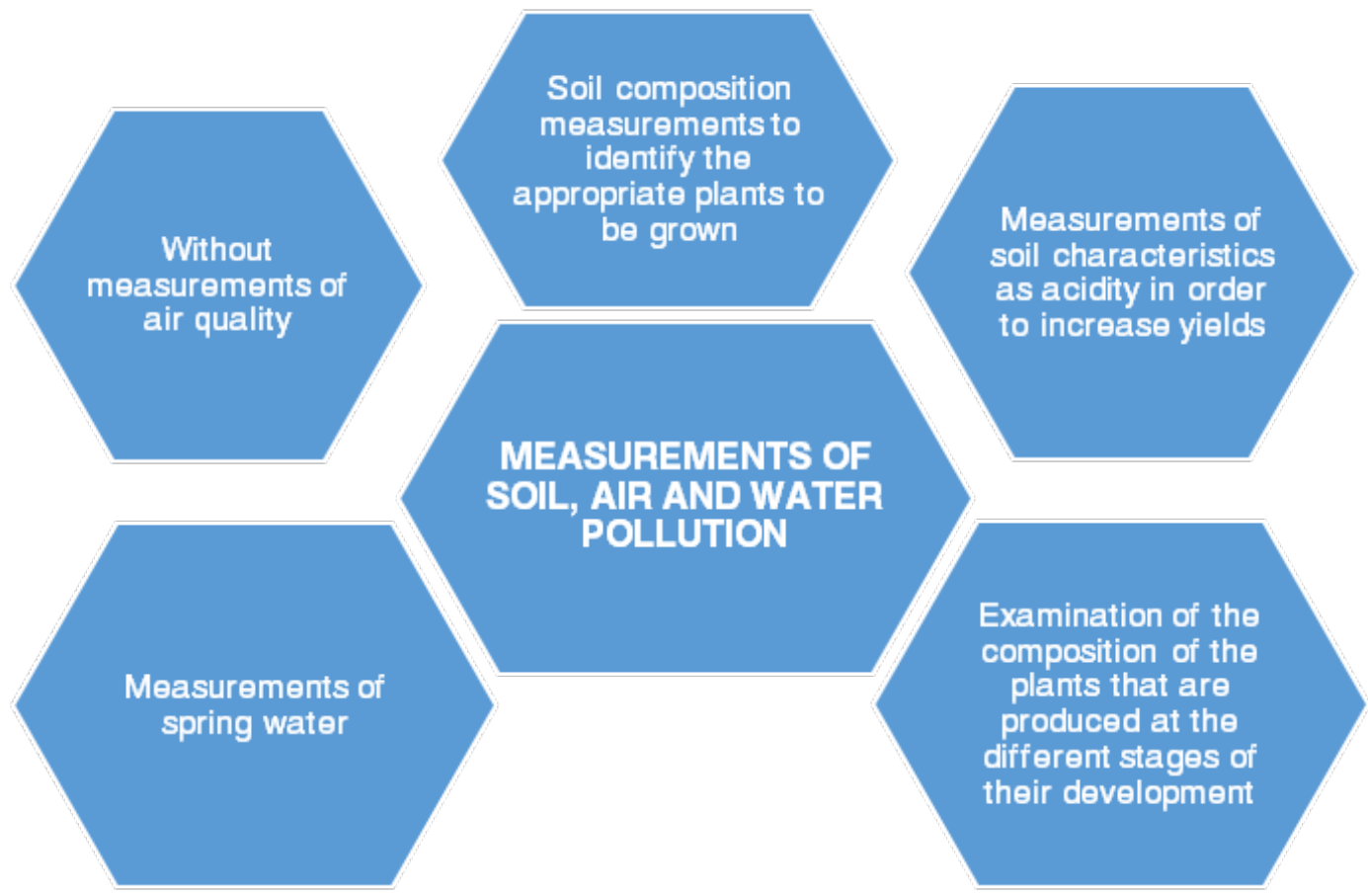

Source: own findings

Consumers of the products are identified by respondents as people who tend to live differently. Most often, these are young people who are interested in organic production, with a certain proportion of them represented by young mothers who are looking for healthy food for their children. Others associate the user of the products from urban agriculture with people who choose what they consume. A third part of the respondents share the view that the users of the products are the producers themselves.
Respondents describe consumers of products from urban agriculture as intelligent people with culture, relatively higher standard of living and good financial opportunities. The interviewed producers indicate that their customers are regular, trust the producer and are familiar with the term organic farming and the ecology of the products they buy. On a number of occasions, consumer choice stems from the fact that the land is on a good environmental level and the products are with a high quality. Figure 3 presents the user's profile of products from urban agriculture. 
Figure 3. Users' profile of products from urban agriculture

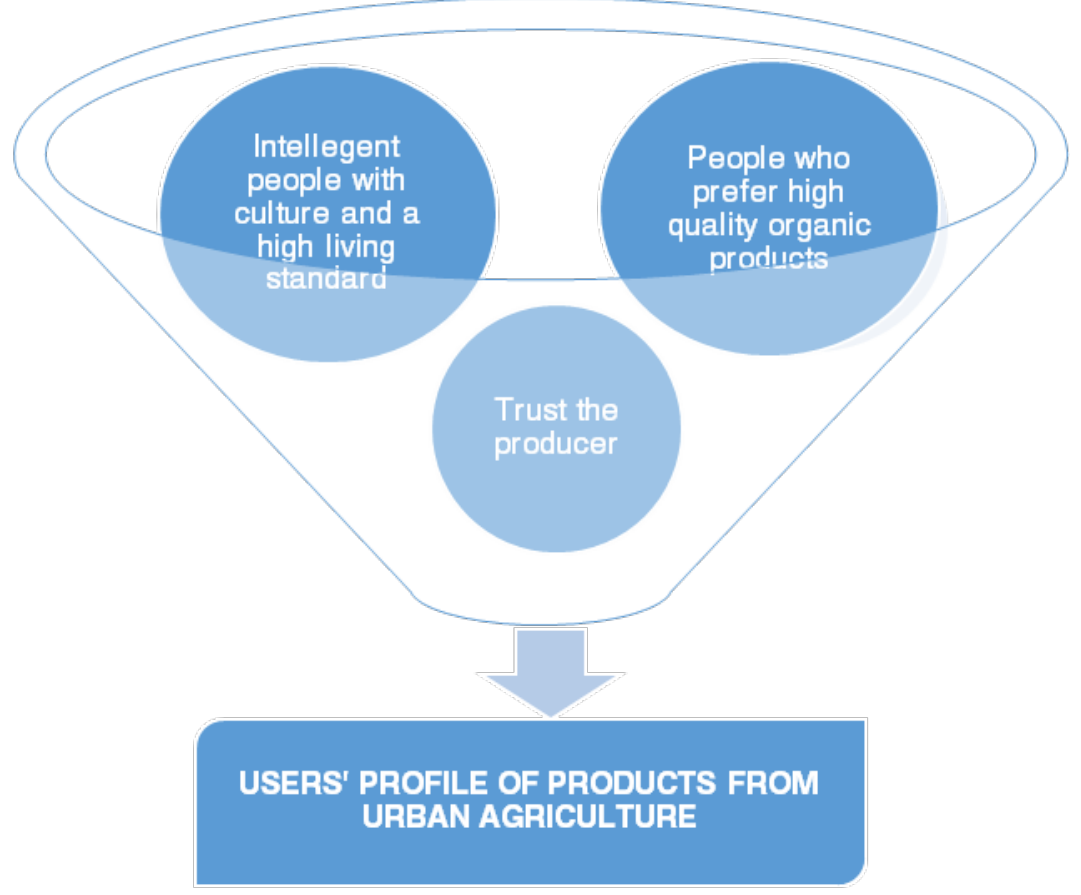

Source: own findings

Together with the profile assessments, the characteristics of urban agricultural products, the production practices that are related to the existing ecological effects of urban agriculture and their opportunities for improving the quality of life, respondents share the view that, urban agriculture creates opportunities for high environmental benefits.

Respondents' views about the environmental impact of urban agriculture are diverse. Most of them are related to achieving sustainable consumption as respondents consider that through implementing urban agriculture it contributes to improving the quality of life, minimizing the use of natural resources, minimizing the use of chemical preparations and toxic materials, limiting the creation of harmful emissions of pollutants. They consider that urban agriculture will increase the satisfaction of life as it creates opportunities for the consumption of healthy, eco-friendly food, creates a cleaner and greener environment. Urban agriculture improves the quality of life in the capital, influencing the psychic comfort of the people, the community spirit, creating opportunities for relaxing.

The environmental benefits are associated with achieving sustainable consumption through the minimal use of natural resources, minimal use of chemicals and toxic materials etc. The majority of opinions connected with the ecological aspects of urban agricultural products is related to the fact that no artificial fertilizers, pesticides and chemicals are used, pest control methods and soil treatments are alternative and environmentally friendly. Table 2 presents the respondents' opinion connected to natural resource conservation. 
Table 2. Main respondents' opinion related to the conservation of natural resources through urban agricultural practices

\begin{tabular}{|l|l|}
\hline $\begin{array}{l}\text { Natural } \\
\text { resource }\end{array}$ & Respondents' opinion \\
\hline Air & $\begin{array}{l}\text { - The environmental benefits are related to creating more green areas in the city and thus impact } \\
\text { on the air quality. Urban agriculture creates different green islands in the city. } \\
\text { - Carbon dioxide is reduced when regional and seasonal products are consumed and transport } \\
\text { emissions are reduced when the production is produced at another place. } \\
\text { - The environmental footprint is reduced by a small and simple step, such as composting, } \\
\text { reducing the greenhouse effect from transport gases. }\end{array}$ \\
\hline Biodiversity & $\begin{array}{l}\text { The land is preserved. The food is absolutely clean from pesticides and any other harmful } \\
\text { substances. The bees that are there are much more than in the other hives because there are no } \\
\text { pesticides. } \\
\text { There is a benefit for bees, even animals, also for the preservation of species diversity. } \\
\text { Urban agriculture has a positive influence on biodiversity preservation that is related to food } \\
\text { production. }\end{array}$ \\
\hline Land & $\begin{array}{l}\text { - The land is preserved through urban agriculture. If the land is not cultivated, it loses all its } \\
\text { properties and is totally destroyed. Soil should be enriched with organic matter, because if there } \\
\text { is no organic matter in the soil, it loses its ability to retain moisture and completely changes its } \\
\text { composition and qualities. } \\
- \text { Organic farming protects the environment, the soil and all the elements of the environment. It } \\
\text { has an ecological effect. } \\
\text { - Urban agriculture protects soil fertility, as organic gardening is usually practiced in organic and } \\
\text { permaculture farming. }\end{array}$ \\
\hline
\end{tabular}

Source: own findings

\section{Conclusions}

Based on the literature review of sustainable urban agriculture, it can be summarized that sustainable urban agriculture combines all the characteristics of urban agriculture, implemented in the concept of sustainability. Sustainable urban agriculture ensures food security and food resources in an environmentally friendly manner by optimizing and saving the use of natural resources, implementing green practices and at the same time creates local employment and encourages the development of the regions.

Shared views on the ecological aspects of implementing urban agriculture can be the basis for the following conclusions:

$\checkmark$ Urban agriculture leads to the recreation and preservation of the soil through the applied production practices.

$\checkmark$ Urban agriculture leads to the preservation of varieties, the diversity of agricultural crops and biodiversity. This ecological aspect is achieved by the use of selected seeds, organic seeds, seeds of their own production or selected from the villages.

$\checkmark$ Carbon emissions and environmental footprint are reduced by the production and consumption of local food. On one hand, fuel costs are saved because of the product's transportation to the point of sale, and on the other hand most of the production is consumed at the place where it is created. The feedstock is short through a direct customer relationship with the producer. 


\section{Articles}

$\checkmark$ Urban farming reduces the amount of waste by avoiding unnecessary packaging since in most cases the production is not packed.

$\checkmark$ Urban agriculture contributes to the creation of an ecological attitude towards the environment and food. By implementing urban agricultural practices, producers achieve environmentally friendly delivery by creating consumer behavior with the preference of organic products.

$\checkmark$ Urban agriculture leads to the creation of green spaces and clean urban environments, thus enhancing air quality and improving the quality of life by preserving the natural conditions of the environment in the cities.

$\checkmark$ The ecological effect of the implementation of urban agriculture is the control over the development of diseases and pests of crops.

Applying urban agriculture will develop more responsible patterns of consumption, especially in the context of sustainability, creating attitudes to environmental behavior through the use of environmentally produced food resources. Nutritional choices will be healthier, which would have a positive impact on the quality of life in the cities.

Urban agricultural producers meet the standards of applying good agricultural practices and ecological production as they use methods as permaculture, biodynamic farming and composting, mulching, and non-fertilizer manufacturing practices. At the same time in most cases, soil and water measurements have not been realized, although respondents consider the natural resources they use clean. In this regard a detailed measurement is needed to determine which land and water resources are suitable for the production of safe food in an urban environment.
Ecological Aspects of Urban Agriculture in the Context of Sustainability

Consumers of products from urban agriculture identify themselves as young intelligent people who are interested in organic production and tend to live differently, select what they consume, have a relatively higher standard of living and good financial opportunities. The choice of consumers to use urban agricultural products is related to the credibility of the producer, the environmentally clean land where high-quality products are produced.

Urban agriculture takes place on a small scale and economic profit is not the goal of agricultural producer in urban conditions. In this regard the most significant purpose of urban agriculture is preserving the quality of natural resources in the cities as soil, water, air, biodiversity, and experimenting with environmentally friendly agricultural practices and technologies.

\section{References}

Basiago, A.,1999. Economic, social, and environmental sustainability in development theory and urban planning practice, The Environmentalist, 19, pp. 145-161, Boston: Kluwer Academic Publishers.

Battersby, J., Marshak, M., 2013. Growing Communities: Integrating the Social and Economic Benefits of Urban Agriculture in Cape Town, Urban Forum, 24 (4), pp. 447 461.

Blanke, M., Burdick, B., 2005. Food (miles) for thought-energy balance for locallygrown versus imported apple fruit. Environmental Science Pollution, 12(3), pp.125-127.

Cofie, O., Adam-Bradford, A., Drechsel, P., 2006. Recycling of urban organic waste for urban agriculture. In R. van Veenhuizen. Cities Farming for the Future: Urban Agriculture for Green and Productive Cities, RUAF Foundation, Leusden. 


\section{Articles}

De Zeeuw, H., 2011. Cities, climate change and urban agriculture, Urban Agriculture Magazine, 25, pp. 39-42.

Deelstra, T., Girardet, H., 2000. Urban Agriculture and Sustainable Cities. In Growing Cities, Growing Food: Urban Agriculture on the Policy Agenda, edited by Bakker N., Dubbeling M., Guendel S., Sabel Koschella U., Zeeuw H., Feldafing: German Foundation for International Development, pp. 43-65.

Draganova, M. et al., DN 05/18 Urban agriculture as a strategy for improving the quality of life of urban communities, project funded by the Bulgaria science fund, project coordinator assoc. prof. Mariana Draganova.

Dubbeling, M., de Zeeuw,H., van Veenhuizen, R., 2010. Cities, poverty and food: multistakeholder policy and planning in urban agriculture. Practical Action Publishing.

EC, 2014, Integrated sustainable urban development, Cohesion policy for the period 2014-2020.

Eigenbrod, C., Gruda, N., 2015. Urban vegetable for food security in cities. A review, Agronomy for Sustainable Development, 35(2), pp. 483-498.

FAO, 2007. Pro tability and sustainability of urban and peri-urban agriculture, Agricultural management, marketing and finance occasional paper, 19.

Ghosh, S., 2004. Food production in cities. Acta Horticulture, International Conference on Urban Horticulture pp. 233-239.
Golden, S., 2013. Urban Agriculture Impacts: Social, Health, and Economic: A Literature Review. Agricultural Sustainability Institute at UC Davis.

Hoornweg, D., Munro-Faure, P., 2008. Urban Agriculture For Sustainable Poverty Alleviation and Food Security, http://www.fao.org/ fileadmin/templates/FCIT/PDF/UPA_WBpaper-Final_October_2008.pdf.

Jamal, M., Mortez, M., 2004. The Effect of Urban Agriculture in Urban Sustainable Development and Its Techniques: A Case Study in Iran, International Journal of Agriculture and Forestry, 4(4), pp.275-285.

Konijnendijk, C., Gauthier, M., Veenhuizen, R., 2004. Trees and cities, growing together, Urban Agriculture Magazine, 13, Leusden, RUAF.

Lohrberg, F., Licka, L., Scazzosi, L., Timpe, A., 2016. Urban Agriculture Europe, Jovis Verlag $\mathrm{GmbH}$.

Mougeot, L., 2010. Agropolis: The Social, Political and Environmental Dimensions of Urban Agriculture, Routledge: Earthscan, IDRC.

Torres-Lima, P., Canabal-Cristiani, B., BurelaRueda, G., 1994. Urban Sustainable Agriculture: The Paradox of the Chinampa System in Mexico City, Agriculture and Human Values, 11(1), pp. 37-46. 